\title{
Supply chain integration: A qualitative exploration of perspectives from plastic manufacturers in Gauteng
}

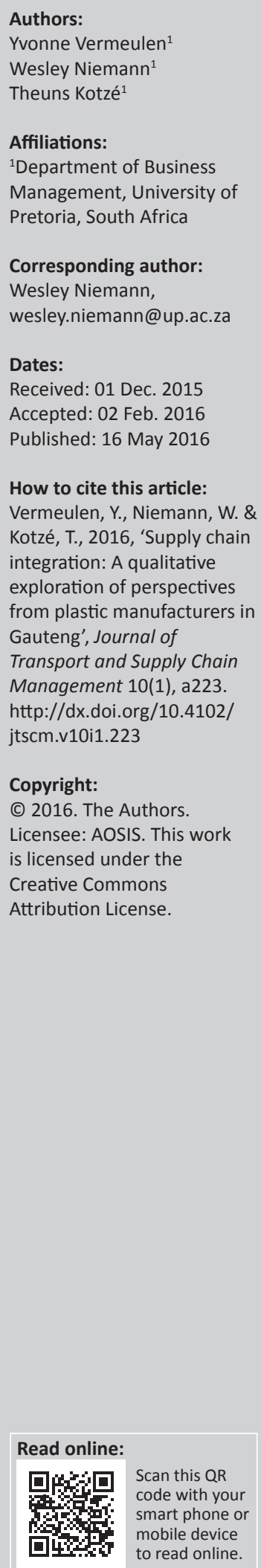

Background: Supply chain integration was identified as a tool to assist an organisation to survive in a competitive marketplace. It was unclear how plastic manufacturers in Gauteng perceived supply chain integration efforts between themselves and their suppliers.

Objectives: This study's main purpose was to investigate the nature and extent of supply chain integration between 10 plastic manufacturers in Gauteng and their suppliers. The focus was on these manufacturers' commitment to and perceptions of supplier integration efforts.

Method: The study was conducted with plastic manufacturing organisations in Gauteng, over a period of 2 months. A total of 10 participants were engaged through semi-structured interviews.

Results: The main findings of the study revealed that commitment and trust were found to be the antecedents of supplier integration and closer collaboration, while customer price pressure and limited available resources served as motivating factors for integration efforts.

Conclusion: It is recommended that organisations must revisit integration efforts when new markets are penetrated and top management support must be revisited using a strategic framework.

\section{Introduction}

\section{Problem statement}

\section{Key focus}

Due to increased competition and deficiencies in their internal capabilities, businesses are increasingly realising that they need to synchronise their internal business operations and strategies with that of their supply chain (SC) partners. This realisation gave rise to the concept of supply chain integration (SCI) (Palma-Mendoza, Neailey \& Roy 2014:167).

\section{Background}

SCI has two fundamental benefits. Firstly, through SCI, organisations can use their SC partners to mitigate their internal deficiencies, which allows them to focus on their core capabilities and strengths, in order to maximise productivity and returns. Secondly, SCI allows for value-added activities between organisations, suppliers and customers to be made more visible (Jin, Fawcett \& Fawcett 2013:206; Klueber \& O’Keefe 2013:296; Papakiriakopoulos \& Pramatari 2010:1298-1299).

\section{Trends}

It is clear from previous studies (Jie, Parton \& Cox 2013:1003-1024; Mackelprang et al. 2014:71-96; Xu, Huo \& Sun 2014:1186-1206) that there is a positive relationship between the level to which organisations pursue enhanced external and internal integration and improvements in organisational performance through improved customer service and reduced costs (Tseng \& Liao 2015:86). However, for SCI to be effective, supply chain management (SCM) initiatives such as the following are needed: network redesign, building stronger supplier relationships and initiating lead time reduction programmes. Organisations are aware of the need for these types of initiatives, yet there is little evidence of these initiatives being implemented (Danese \& Romano 2010:221).

Beth et al. (2003:64) indicate that, despite much technological and process advancement in SCM, '... an agile, adaptive SC remains an elusive goal'. Jin et al. (2013:206) suggest that their research answers an important question: 'Why are companies not doing better?' According to them, organisations lack commitment to integrating skills and processes; therefore, few companies take advantage of the improved organisational performance opportunity provided by SCI (Jin et al. 2013:206). 
Top management are aware that the decisions they make influence an organisation's strategy and that correct decisions will ensure increased competitive advantage ( $\mathrm{Xu}$ et al. 2014:1189). To ensure effective SCI, managerial views need to be changed and lack of commitment to SCI needs to be addressed (Jin et al. 2013:206). Evidence exists that top management favour integration efforts and collaborative relationships (Jie et al. 2013:209), but this requires a strategic framework as well as top management's commitment to link integration efforts both internally and externally with SC partners (Beheshti et al. 2014:28).

Fawcett and Magnan (2002:358) point out that the marketplace has become more competitive due to globalisation, customers demanding better service and the advancement in technology. Recent research by Han et al. (2013:230-252) identified SCI as a tool that could assist companies to survive in a competitive marketplace. With increased competition, both SC uncertainty and organisational risk increases (Prajogo \& Olhager 2012:515).

$\mathrm{Xu}$ et al. (2014:1186-1206) suggest that the antecedents of SCI, including relationship commitment, power, trust and dependence, deserve further research attention. This suggestion is supported by several other researchers, including Geménez, Van der Vaart and Van Donk (2010:583-610), Han et al. (2013:230-252), Huo (2012:596-610), Kocoglu et al. (2011:1630-1649), Liu et al. (2011:322-346), Moshkdanian and Molahosseini (2013:184-192), Tseng and Liao (2015:82-106), as well as Wiengarten et al. (2014:51-63). It is also supported by researchers, such as Alfalla-Luque, Marin-Garcia and Medina-Lopez (2012:242-257) and Salam (2011:358-382), who investigated the positive relationships between SCI and organisational performance.

\section{Objectives}

Jin et al. (2013:206) indicate that the environments in which organisations conduct business evolve over time. SCI efforts and their effect on organisational performance must, therefore, be reviewed continuously. Research indicates that the link between SCI and organisational performance may not be well grounded, as research findings cannot be applied to all emerging economies (Liu et al. 2011:322).

A knowledge gap exists regarding the perceptions that plastic manufacturers in Gauteng have about SCI with their suppliers, as well as about these manufacturers' commitment to SCI and their efforts in this regard. The purpose of this exploratory study was, therefore, to investigate the nature and extent of SCI between 10 plastic manufacturers in Gauteng and their suppliers. The focus was specifically on these manufacturers' perceptions of and commitment to SCI with their suppliers, as well as on the nature of their SCI efforts.

The study sought to answer the following research questions:

- How committed are plastic manufacturers in Gauteng to SCI with their suppliers?

- What is the nature of the SCI efforts that plastic manufacturers in Gauteng engage in with their suppliers?
- How committed are plastic manufacturers in Gauteng to sharing and improving the visibility and quality of the information shared with their suppliers?

- What influence do relationships and trust dynamics have on the SCI efforts of plastic manufacturers in Gauteng?

- Do plastic manufacturers in Gauteng perceive SCI with their suppliers as providing an important sustainable competitive advantage?

Current literature on SCI is reviewed in the next section.

\section{Literature review}

SCI has received a lot of attention over the past few years; however, despite widespread acknowledgement of the importance of SCI, certain sectors have not yet investigated and adopted this SCM strategy (Simon et al. 2014:286).

Globalisation, advances in production efficiency, shorter production lead times and the drive towards reduced inventories are prompting organisations to rapidly change their operational processes. Industries going through this rapid change need to explore strategic alliances, improved customer relationship management practices, improved information quality among business partners and lean systems (Jie et al. 2013:1004). Commoditising due to less differentiated products, intensified competition and low margins drive organisations to explore SCI for efficiency improvements (Guan \& Rehme 2012:191-196).

SCI is a decisive factor that should be investigated if organisations are to survive, grow and achieve a competitive advantage in an increasingly competitive environment (Danese \& Romano 2010:220). Organisations are entering a period in which independence of operations can no longer provide a competitive advantage. Market success now depends on how organisations integrate with their SC partners (Simon et al. 2014:272-273). However, Bagchi and Ha (2005:276) caution that not all SCI are beneficial. Some SCI efforts should not focus on holistic integration, but rather on establishing a semi-integrated SC with partners who perform certain processes better than the organisation. Literature on internal organisational integration; integration with suppliers and customers; the influence of information visibility, sharing and quality on SCI; and long-term partnerships, commitment and trust as enablers of SCI are reviewed below.

\section{Internal organisational integration}

Internal integration is the extent to which an organisation develops organisational strategies, practices and processes that can be synchronised in order to ensure that they add value to the organisation's customers (Flynn, Huo \& Zhao 2010:59). Internal organisational integration assists with this process by leveraging resources and capabilities of functions for purposes of product development and reducing waste, which provide increased value to customers (Huo et al. 2014:371). Internal integration refers to the integration of departmental functions and activities in order to improve performance 
across departmental boundaries, increase customer service levels and ensure a competitive advantage (Basnet 2013:153). SCM stretches over several organisational functions, including operations, marketing, sales, manufacturing and information systems. These functions usually operate in isolation, and these 'silos' can cause internal conflict (Chelariu, Asare \& Brashear-Alejandro 2014:332); contrarily, internal integration indicates that the functions in an organisation must work together in an integrated way and that the barriers that cause departments to operate in 'silos' need to be broken down (Zhao et al. 2011:19). Deficient internal integration will cause weak communication, reduce teamwork and increase intracompany conflict, thus making communication and external integration difficult (Huo 2012:604).

When organisations include internal integration efforts in their strategy, SC integration efforts are strengthened, customer service levels are improved and there is a significant improvement in the organisation's bottom line (Basnet 2013:153-155). Changes in an organisation's market environment (e.g. shorter lead times, stronger price competition and export growth) and a focus on value-adding strategies should motivate organisations to enhance their integration efforts (Jie et al. 2013:208).

Market positioning and information technology strategies have a favourable effect on SCI (Tseng \& Liao 2015:96). An organisation's market positioning strategy is a vital driving force for SCI because the chosen strategy influences roles, functions and the resources employed (Guan \& Rehme 2012:196). The market positioning also mirrors how the organisation creates value for its customers; therefore, the market orientation of the organisation is a fundamental aspect of an organisation's strategy (Lui et al. 2011:325).

\section{Integration with suppliers and customers}

Historically, relationships with suppliers were adversarial and the general approach was to accept the lowest price; so, little integration and collaboration were done (Jie et al. 2013:207). However, organisations are now increasingly focusing on their core capabilities and relying on suppliers to manage non-core activities - which means dependency on suppliers is increasing (Moshkdanian \& Molahosseini 2013:188).

Competitive advantage can be increased by promoting effective communication and improving personal relationships with suppliers; therefore, organisations need to evaluate their supplier relationships and build long-term relationships. This can be done through meetings with suppliers and sharing information with suppliers, in order to ensure that joint strategies are developed (Danese \& Romano 2010:221). Guan and Rehme (2012:187) indicated that vertical integration with suppliers is an antecedent to SCI, and Simon et al. (2014:286) concluded that supplier relationship management is a crucial strategy, which needs more attention from organisations. Organisations are more likely to engage in collaborative supplier relationships because of the standards that have been set in this area by leading organisations such as Toyota and General Motors (Jie et al. 2013:209).

Supplier integration enhances customer integration efforts, organisational effectiveness and efficiency, but customer integration alone does not affect efficiency (Danese \& Romano 2010:222). A higher degree of customer integration influences organisational performance more positively than supplier integration, due to organisations being rewarded by customers, who conclude more sales transactions. However, in order to achieve the highest possible level of organisational performance, all integration dimensions must be developed (Huo 2012:605).

Danese and Romano (2010:220-230) asked the question: 'Are there synergies that a firm could or should exploit by implementing customer and supplier integration?' Customer integration is needed in order to intensify customer loyalty and increase the organisation's market share ( $\mathrm{Xu}$ et al. 2014:1191). It is also related to a broad range of performance results (Mackelprang et al. 2014:82). Solutions can be obtained to increase efficient performance and solve demand uncertainty and demand volatility by customers sharing their demand information through point-of-sale data, implementing vendor-managed inventory systems and focusing on alignment of demand between SC partners. These solutions will, in turn, reduce costs and increase an organisation's performance (Danese \& Romano 2010:221).

\section{The influence of information visibility, sharing and quality on supply chain integration}

SCI mainly consists of information sharing and operational alignment. Information sharing entails real-time clarity and availability of information, while operational alignment involves the sharing of knowledge and decisions across the SC (Liu et al. 2011:324). Information sharing has a positive impact on operational performance (Moshkdanian \& Molahosseini 2013:188) and on new product development and commercialisation (Liu et al. 2011:325). The effective sharing of information between partners is crucial for organisations to compete in an increasingly competitive market, (Tseng \& Liao 2015:85) and customer value creation can only be realised when organisations share more than just transactional data (Moshkdanian \& Molahosseini 2013:189).

Exchanging information assists suppliers to align their strategic, operational and tactical decisions to improve delivery to their customers (Han et al. 2013:233-234), reduce the cost of inventories, highlight customer demands and react to changing market determinants (Lui et al. 2013:325). Information technology and sharing information between SC partners are the forerunners of SCI; it includes the technological system and the social characteristics required to enable sharing of information and trust between partners (Prajogo \& Olhager 2012:515). When organisations consider their SC relationships to be a priority, information sharing becomes crucial for commitment purposes (Salam 2011:365). As commitment between SC partners is enhanced, the inclination to share information is also strengthened (Zhao et al. 2011:21). 
Integrated information technology for SCM is important for integration efforts, and this must be considered independently from internal customer and supplier integration efforts. Information technology creates a virtual SC network that aligns all the activities of all partners with the demands of the organisation's customers (Beheshti et al. 2014:20); this intensifies the potential for SCI ( $\mathrm{Xu}$ et al. 2014:1190). Information technology assists organisations to manage the increasing magnitude of information between SC partners and provide real-time information on inventory, planning and order status between these partners. Data gathered from the information systems assist by aligning supply and demand in the SCs (Prajogo \& Olhager 2012:516). Therefore, SC partners need to adopt more appropriate systems, in order to increase the quantity and to improve the quality of their information (Jie et al. 2013:1003-1024).

A few organisations provide suppliers and customers with information through information systems (Bagchi \& Ha 2005:277); however, information technology implementation efforts fail if organisations cannot exchange the most crucial and accurate data necessary for suppliers and customer (Prajogo \& Olhager 2012:516). In addition, information technology investment may not result in performance improvement in the short-term, and this needs to be assessed over the long-term (Tseng \& Liao 2015:96).

The quality of information sharing between SC partners was highlighted as the most significant element for SC performance, as SC partners use the information to make decisions that affect competitiveness, and management action is necessary to improve information quality and information visibility (Jie et al. 2013:1009). In the rapidly changing business environment, advanced SC systems have proved to impact business and SCs in a positive manner (Jie et al. 2013:1003-1004), and information sharing between partners is the most important aspect to attaining SCI (Moshkdanian \& Molahosseini 2013:187).

\section{Long-term partnerships, commitment and trust as enablers of supply chain integration}

Salam (2011:364) defines trust as SC partners' willingness to engage with each other and share expertise. Trust thus increases dependability between SC partners and fosters the realisation that the partnership can deliver long-term benefits through reliability and integrity (Salam 2011:364-365). Commitment, in turn, refers to an agreement or promise to do something in the future (Salam 2011:360). Commitment is the desire from both parties to maintain and strengthen their respective relationships (Salam 2011:360-361).

Strategic SC alliances, trust and commitment are important antecedents of improved SC responsiveness, efficiency and customer satisfaction. The aforementioned antecedents can impact partnerships significantly through the quality of communication shared between partners, trust, coordination of activities and the inter-dependence of those activities, joint problem solving for effective and efficient conflict resolution and joint continuous improvement efforts (Jie et al. 2013:1005-1007).
Jin et al. (2013:206) argue that strategic organisational concerns relating to competitive advantage may reduce trust and commitment between partners if they are fighting for scarce resources and fear losing proprietary information - which means that efforts to integrate with partners will be limited. Trust and commitment can only be achieved with complete willingness to share the information that is necessary for the partnership to perform effectively. Trust is important in order to develop competitive SC structures through vertical integration, which enhances value-added activities and collaboration between SC partners (Jie et al. 2013:1007).

The ability of an organisation to integrate with its partners relates directly to the organisation's inclination regarding partnerships and its commitment to partnerships (Zhao et al. 2011:18). Commitment can be seen in efforts to strengthen SC partnerships through stabilising relationships and making sacrifices in the short term for the greater good of the relationship in terms of long-term benefits. Once this commitment is established, collaboration exists between SC partners; and as the relationship matures, dependence increases and the partners increasingly realise the need to work on the strategic relationship (Salam 2011:360-361).

Collaboration and long-term partnerships are viewed as the most influential factors through which organisations can achieve a competitive advantage, due to the benefits arising from SC partners sharing knowledge and resources (Vaidya \& Hudnurkar 2013:293). Relationships between manufacturing organisations and suppliers have changed dramatically in the past few years, including a move from short-term contracts to long-term relationships- which reduces the supplier base of organisations- and a change from armslength supplier relationships to suppliers being incorporated into organisations as key strategic alliances. This has motivated suppliers to invest in resources to improve relationships with their customers (Prajogo \& Olhager 2012:516).

\section{Research method and design Materials}

The unit of analysis in this study was organisation-supplier integration efforts. Ten employees from 10 different manufacturers in the plastic industry in Gauteng participated in the study, with the main source of data being semistructured interviews conducted with these participants during August and September 2015. The researcher works in the plastic manufacturing industry and experienced specific problems with regard to SCI efforts. The industry was thus chosen to investigate SCI problems. Convenience sampling was used to select the study participants. The job titles of participants included buyers as well as SC, logistics and procurement managers.

\section{Setting}

Ten face-to-face semi-structured interviews were conducted in the participants' offices or in a meeting room at their offices and were recorded with their permission. The interviews lasted $36 \mathrm{~min}$ on average. 


\section{Design}

The study used a descriptive qualitative research design. According to Plano Clark and Creswell (2015:289), the purpose of a descriptive qualitative research design is to explore different perspectives on a topic by identifying underlying themes from discussions with participants. In this study, a deeper understanding of SCI efforts and commitments towards SCI was required, thus a descriptive qualitative design was most fitting.

\section{Procedure}

Based on the literature review, a discussion guide was developed and a pilot study was conducted with a single participant to check the suitability of the questions. The pilot interview was recorded with the participant's permission. The discussion guide and a written reflection on the pilot test were next submitted for peer assessment to evaluate the quality and reliability of questions, check for researcher bias and determine if any important questions had been omitted. Minor changes were made to the discussion guide and data collection commenced. The final discussion guide is included in Appendix 1.

The interview recordings were transcribed by the interviewer and a commercial transcription service provider with experience in transcribing qualitative interview recordings. The verbatim transcripts included all pauses and spoken 'gestures' (Creswell 2012:239). The researcher listened to each recording while assessing the accuracy of the transcripts. Sentences were amended to accurately reflect the recorded interview. Interviews were transcribed a few days after the interview, and data analysis was done after the transcript approval.

\section{Data analysis}

Thematic analysis, a method used to identify, organise and highlight meaningful patterns across a data set (Braun \& Clarke 2012:57), was done. Preliminary exploratory analysis (Creswell 2012:243) was done with the collected data, by listening to the audio-recordings while reading the interview transcripts. After familiarisation, codes were generated and the data coding process commenced, with text segments being identified and labelled (i.e. applicable text segments were marked and a descriptive label added to each segment to summarise the meaning). During the process, a master list of codes was generated and the codes were reapplied to similar segments of data. Once all the data were coded, the master list of codes was investigated to identify and combine redundant or similar codes (Braun \& Clarke 2012:61). Identification and refinement of themes continued. After coding, related codes were combined into themes that formed a pattern of meaning; these were identified and labelled with a descriptive name (see Appendix 2). The final themes were established and evaluated to determine if the themes captured all the data relevant to the study's research questions. This assisted in identifying patterns in the data and organising patterns into themes, to provide meaning in terms of the transcripts (Braun \& Clarke 2012:63-65).

\section{Results}

The research identified three main themes related to SCI efforts, namely (1) the organisation and integration, (2) SC partnership and (3) SC information management. These three main themes and their related sub-themes are discussed below. For each main theme and sub-theme, illustrative quotations will be provided from participants. Parallels will also be drawn between participants' inputs and the reviewed literature. The main themes and sub-themes are summarised in Table 1.

\section{The organisation and integration}

The organisation and integration refers to the strategies, practices and processes the organisation develops and implements to assist with SCI (Flynn et al. 2010:59; Huo et al. 2014:371).

\section{Top management support}

Top management support can be described as the perceived support from top management for integration, both internally and externally. Commitment from top management is necessary to link efforts with SC partners (Behesti et al. 2014:28). Participants identified support from top management;

TABLE 1: Identified themes provided from the research by participants.

\begin{tabular}{|c|c|c|c|c|c|c|c|c|c|c|}
\hline \multirow[t]{2}{*}{ Participant } & \multicolumn{2}{|c|}{$\begin{array}{c}\text { The organisation and } \\
\text { integration }\end{array}$} & \multicolumn{5}{|c|}{ SC partnership } & \multicolumn{3}{|c|}{ SC information management } \\
\hline & $\begin{array}{c}\text { Top } \\
\text { management } \\
\text { support }\end{array}$ & SCl strategy & Collaboration & Trust & Commitment & $\begin{array}{l}\text { Competitive } \\
\text { pricing }\end{array}$ & $\begin{array}{l}\text { Shared and } \\
\text { available } \\
\text { resources }\end{array}$ & $\begin{array}{c}\text { Sharing of } \\
\text { information }\end{array}$ & $\begin{array}{c}\text { System } \\
\text { integration }\end{array}$ & $\begin{array}{l}\text { Technological } \\
\text { requirements }\end{array}$ \\
\hline P1 & $x$ & $x$ & $x$ & $x$ & $\mathrm{x}$ & - & $x$ & $x$ & $x$ & - \\
\hline P2 & $\mathrm{x}$ & $x$ & $x$ & $x$ & $x$ & $x$ & $x$ & $x$ & $x$ & - \\
\hline P3 & $x$ & $x$ & $x$ & $x$ & $x$ & - & - & $x$ & $x$ & - \\
\hline P4 & $\mathrm{x}$ & $x$ & $x$ & $x$ & $\mathrm{x}$ & $x$ & - & $x$ & $x$ & - \\
\hline P5 & $x$ & $x$ & $x$ & $x$ & $x$ & $x$ & - & $x$ & - & - \\
\hline P6 & $x$ & $x$ & $\mathrm{x}$ & $x$ & $x$ & - & - & $x$ & - & $x$ \\
\hline P7 & $x$ & $x$ & $x$ & $x$ & $x$ & - & - & $X$ & $x$ & - \\
\hline P8 & $x$ & $x$ & $x$ & - & $x$ & - & $x$ & $X$ & $x$ & $x$ \\
\hline P9 & $x$ & $x$ & $x$ & $x$ & $x$ & $x$ & $x$ & $x$ & $x$ & - \\
\hline P10 & $x$ & $x$ & $x$ & $x$ & $x$ & - & - & $x$ & $x$ & $x$ \\
\hline
\end{tabular}

$\mathrm{SCl}$, supply chain integration. 
however, one participant felt that they could get more support from top management:

Um, [pause] I do not know if it is for them as a high priority because I do not think they burned their fingers enough ... I do not feel I have enough support from top management. (P2, Female, Supply Chain Manager - translated)

I think Integration starts with management. If management is not open with Integration ... your employees in your department will not fall for it. (P3, Male, Logistics Manager - translated)

\section{Supply chain integration strategy and the organisation}

The perceived meaning of SCI, from participants interviewed and their organisation's strategy, paints a picture of the importance of SCI in the organisation's strategy. Internal organisational integration favoured external integration and participants stressed the need to start integrating more externally. There was, however, little knowledge of their competition's strategies and integration efforts. One organisation had to change their integration efforts to adapt to new markets they were penetrating:

Our ability to appeal to the retail environment [pause] uhm that is a firm strategy of our organisation. That, the diversification of product range, that comes with selling to the retail environment, requires a, a very different approach from a supply chain point of view. (P8, Male, Procurement Manager)

A house without a plan is always going to fall down you know. And, and it's likewise with a business, you know, if there's no integration efforts which are basically built into the structure of the company, [pause] you'll be running a rat race. Even though you win the race, you'll still be a rat. You know. So it's important for us to have a strategy. (P10, Male, Raw Material Buyer)

These observations are in line with existing literature on SCI. If organisations want to achieve an advantage in the market, or expand their market share, SCI is the decisive factor that must be embraced and investigated (Danese \& Romano 2010:220). When organisations include integration efforts in their strategy, SCI efforts are strengthened (Basnet 2013:153). A competitive strategy is the enabler between SCI and organisational performance (Huo et al. 2014:369). Jie et al. (2013:209) state that evidence exists which indicates that top management favours integration efforts, and that these efforts require a strategic framework (Behesti et al. 2014:28) as well as the elimination of structural barriers by management to ensure effective SCI (Jin et al. 2013:206).

SC partnership: SC partnership can be defined as the management of a relationship between a supplier and customer that includes close collaboration, trust, commitment, transparency and information and resource sharing to benefit both parties (Jin et al. 2013:205).

\section{Collaboration}

Collaboration can be described as working with suppliers to determine improvements beneficial to both the customer and supplier (Jin et al. 2013:205). Collaboration is relevant to the study because it forms the basis of a relationship with a supplier. Participants indicated that collaboration with suppliers is not just based on price and quality, but is based on a relationship. Supplier bases were reduced and suppliers were chosen because of their skill sets and strengths after risks and threats were investigated. Weaknesses were addressed using supplier evaluation tools. Two participants indicated that price is still predominantly the order winner, but one participant did not agree with their respective organisation's view and indicated that service and quality are more important. Participants indicated changing attitudes from suppliers and their organisations:

There is a traditional and perhaps outdated idea that uhm, [pause] you as a customer have some kind of ... customer first [pause] mentality ... partnerships with suppliers ... that make the big difference ... we treasured ... suppliers, who had excellent technical support ... we reduced our supplier base dramatically $\ldots$ at a very high risk ... of not being ... competitive on price. But oh, we, we reap the benefits. (P8, Male, Procurement Manager)

\section{Trust}

Trust is the mutual belief between supplier and customer that the other is reliable and truthful (Salem 2011:360-361). It was highlighted as being stronger when there was more experience with the supplier. Trust is important due to the sensitive nature of the information exchanged between the parties and used to make decisions. Organisations implemented non-disclosure agreements to indicate the importance of information sensitivity. Participants noted the importance of trust and felt that their reputations are at risk. Trust increases dependability between SC partners, and could lead to long-term benefits, and is therefore an important aspect of SCI efforts (Salem 2011:364), as indicated by the participant quotes:

Things change, there is a lot of [pause] volatility in the market at the moment ... trust is absolutely critical for us ... we cannot work with a supplier if there is no trust, impossible. We will not ... trust in a relationship, honesty, integrity go hand in hand for us ... our reputational risk is absolutely critical for us. (P7, Male, Purchasing Manager)

If you do not have trust, then what do you have? [Laughs]. There must be a trust relationship between both parties. (P3, Male, Logistics Manager)

\section{Commitment}

Commitment can be described as a pledge, or promise, between a supplier and customer whereby they agree to be dedicated to the relationship and the SC cause. Commitment and trust is an expectation that both parties will consistently meet their obligations in the SC (Jie et al. 2013:1005). Participants mentioned that commitment is a two-way street and, if a commitment is not honoured, it puts pressure on the SC. Overall, participants were happy with perceived commitments, whereas one participant struggled with suppliers' commitments. Commitment can be directly related to the ability of an organisation to integrate with partners, as shown by participant quotes:

So trust absolutely ... it's just like commitment the two go hand in hand. You can only be committed if there is not trust. (P1, Female, Procurement Manager - translated) 
So, commitment ... is a two way street so it's I commit to you and [pause] the supplier must commit to you, you know, it's a twoparty thing. (P3, Male, Logistics Manager - translated)

\section{Competitive pricing}

Competitive pricing can be described as setting a price for a product or service in line with what the competition or market is charging (Guan \& Rehme 2012:189). Transparency, as well as increased collaboration, was highlighted as influencing customer price pressures. One participant mentioned that the best price wins, but it was the same participant who struggled with commitment from suppliers. Competitive pricing allows closer collaboration and is, therefore, relevant to the study, as is illustrated by the following quotation:

So we have much more regular contact specific about pricing [pause] because we also uhm, are pressurised from our customers. If Company $\mathrm{X}$ price decrease, then they know it and they want to know when, when they see a, their decrease. (P2, Female, Supply Chain Manager - translated)

\section{Shared and available resources}

Suppliers and customers share each other's resources and/or assist one another by making resources available for the benefit of the SC. Cash flow was underscored as a main concern to organisations. Organisations emphasised that they are more vulnerable where they spend money unnecessarily and could not absorb resulting overstocks. Pressure from overstocks and cash flow constraints improved integration with suppliers, as the following quotes indicate:

We must keep inventory as low as possible. So um, because of the [pause] pressure on us over inventory [pause] um, my integration with the suppliers is better. (P2, Female, Supply Chain Manager - translated)

Cash flow ... remains an issue in our business ... to know exactly what stock is available at Company S ... so, having that information for plain sight ... Everyone is more sensitive about where they spend their money ... people [are] becoming stricter. Before, people did not mind holding on to stock for months on end but uh, it is purely a cash flow issue, it is, it's purely the economy that we are in ... people need just that little bit more information. (P8, Male, Procurement Manager)

These observations are in line with the reviewed literature and indicate that trust, commitment and collaboration are crucial for consistent performance between SC partners (Jie et al. 2013:1005-1007). Jin et al. (2013:206) indicate that strategic dealings reduce trust and commitment due to partners fighting for the same resources and fearing losing proprietary information. Participant observations differed from this view because organisations stopped buying from suppliers if they felt they could not trust them. Reduced available resources and market price pressures strengthened collaboration with suppliers, as indicated by Guan and Rehme (2012:191-196).

SC information management: SC information management can be described as the sharing of SC information between suppliers and customers (Guan \& Rehme 2012:190). This information can be shared with the suppliers' supplier and is a mutual process of sharing formally or informally through information systems.

\section{Sharing of information}

Information sharing is crucial to integrating with suppliers. Shared information observed by participants includes forecasts, direction of business and new projects. Certain types of information are not shared with suppliers and information sharing differed from one supplier to the next. Information sharing also differed between who the participants perceived as critical and non-critical suppliers. Critical and non-critical suppliers are distinguished through risk analysis conducted on the organisations' supplier base. Participants mentioned that it is easier to obtain information from their suppliers and customers. Mostly, more easily obtained types of information mentioned were limited to forecasts and new projects. Transparency was mentioned as an important aspect of information sharing. The following quotes reflect on information sharing:

I am more than comfortable about ... the information in terms of the direction of our company ... if you are not in a position to discuss the future ... and what you are working on now and where you want to be with your supplier, then it is impossible for them to align their goals with yours. (P8, Male, Procurement Manager)

It gives them an indication how busy you are, if you [are] growing, so all of that sort of thing. (P6, Male, Supply Chain Manager)

\section{System integration}

System integration refers to information systems being implemented between supplier and customer (Tseng \& Liao 2015:85). No evidence was found that the plastics manufacturers included in this study integrated their systems with their suppliers, and participants seemed to prefer personal interactions with suppliers. One participant mentioned that while the infrastructure existed, they did not see any benefit in using it. Internal integrated systems assisted with information visibility, whereas a lack of internal system integration left participants feeling blind:

Because at this stage, you are blind ... you must believe that the guy on the other side of the phone tells you. (P2, Female, Supply Chain Manager - translated)

I don't think in the, in the short or medium term [pause] there is any plans to do that ... I cannot [pause] really see that it will add any benefit that is why we will not do it. (P7, Male, Purchasing Manager)

\section{Technological requirements}

Developments in technology improvements through information technology applications strengthen information sharing through the possibility to integrate standalone information systems (Tseng \& Liao 2015:85). The participants mentioned that senior management is thinking along these lines and receiving requests for system integration. One participant mentioned that their biggest supplier was conducting business online. These requirements would ease integration with suppliers: 
And they have got a [pause] fairly easy portal ... you log on to their system, you can see their stock at any time, orders are placed online. And the system is very, very easy. (P8, Male, Procurement Manager)

But with those managers that I do deal with, that is the thinking, yes. (P10, Male, Raw Material Buyer)

These observations are in line with reviewed literature indicating that information sharing has a positive impact on reduced inventories (Moshkdanian \& Molahosseini 2013:188) and new product developments (Liu et al. 2011:325). Benefits were realised when organisations shared more than simply transactional data (Moshkdanian \& Molahosseini 2013:189) and suppliers could align their strategic goals and directions with the organisations (Han et al. 2013:233-234). There was, however, little evidence of information technology helping to align partner activities (Behesti et al. 2014:20), and it was found that organisations still prefer personal interactions. One organisation was actively involved in investing in information technology to assist with operations and provide real-time inventory information, thereby more effectively managing information flow. This finding is in line with the findings by Bagchi and Ha (2005:277), who found there are few organisations capable of providing information through implemented information systems.

\section{Ethical considerations Potential benefits and hazards}

The study was approved by the Research Ethics Committee of the Faculty of Economic and Management Sciences at the University of Pretoria during July 2015.

\section{Recruitment procedures and informed consent}

All participants read and signed an informed consent form. The consent form explained the purpose of the study, indicated that participation was voluntary and also stipulated that participants could withdraw from the study at any time.

\section{Data protection}

Assurance was given of anonymity and confidentiality. The guarantee of confidentiality encouraged participants to respond honestly. As indicated in Table 2, pseudonyms were used to protect the identity of participants and organisations.

\section{Trustworthiness}

The right of participants to trustworthy research is important (Cooper \& Schindler 2014:38). The following criteria were used to ensure the trustworthiness of the findings: credibility, dependability, confirmability, transferability and authenticity. The strategies used to enhance the quality of the research and the elements used to improve trustworthiness are discussed below.

\section{Reliability}

To ensure transferability and authenticity (Polit \& Beck 2012:585), a descriptive background to the research was given; an interview discussion guide and clear process for data analysis were included and detailed descriptions were provided of participants; steps were taken to ensure the data provided awareness of feelings and tone of participants. Confirmability was ensured by linking the analysed data with the literature reviewed.

\section{Validity}

All interviews were conducted by the same interviewer. Data collection, preparation and analysis of the study were recorded in detail, to ensure dependability and consistency of the research. Steps were taken to ensure data were not changed and truthfully reflected the participants' opinions.

\section{Discussion Outline of the research}

The aim of the study was to explore the perspectives and efforts of plastic manufacturers in Gauteng, in relation to SCI with their suppliers. The main theoretical findings indicate that organisations are aware of SCI and suggested that the participants and their organisations have the same working definition of SCI.

Participants identified collaboration, trust and commitment as antecedents to integrating with suppliers. The implications of these antecedents are in line with reviewed literature and indicate that they enable improved SC responsiveness, efficiency and customer satisfaction (Jie et al. 2013:1005-1007). Commitment efforts were mostly executed through one-onone, personal interactions with suppliers. Trust was indicated

TABLE 2: Summary of participant and organisation details.

\begin{tabular}{|c|c|c|c|c|c|c|c|c|}
\hline Participant & Job title & Gender & Firm & $\begin{array}{l}\text { Number of } \\
\text { suppliers }\end{array}$ & $\begin{array}{l}\text { Number of } \\
\text { employees }\end{array}$ & $\begin{array}{l}\text { Multiple } \\
\text { branches }\end{array}$ & $\begin{array}{l}\text { Experience in } \\
\text { years }\end{array}$ & $\begin{array}{c}\text { Duration of } \\
\text { interview }\end{array}$ \\
\hline P1 & Procurement Manager & Female & S1 & 218 & 160 & Yes & 10 & 55.46 \\
\hline P2 & Supply Chain Manager & Female & S2 & 50 & 125 & Yes & 20 & 59.36 \\
\hline P3 & Logistics Manager & Male & S3 & 15 & Unknown & Yes & 15 & 28.58 \\
\hline P4 & Production Manager & Male & S4 & 6 & 1000 & Yes & 2 & 31.43 \\
\hline P5 & Inventory Controller & Female & S5 & 350 & 200 & Yes & 3 & 22.27 \\
\hline P6 & Supply Chain Manager & Male & S6 & 40 & 260 & Yes & 20 & 27.49 \\
\hline P7 & Purchasing Manager & Male & S7 & 150 & 1000 & Yes & 18 & 28.28 \\
\hline P8 & Procurement Manager & Male & S8 & 200 & 160 & Yes & 3 & 46.49 \\
\hline P9 & Procurement Manager & Male & s9 & 300 & 500 & Yes & 6 & 31.46 \\
\hline P10 & Raw Material Buyer & Male & S10 & 30 & $500+$ & Yes & 9 & 29.33 \\
\hline
\end{tabular}


as a crucial antecedent to doing business with suppliers. Most participants indicated that they would not buy from suppliers unless they trusted them. Sensitive information was shared between companies as they saw fit. This finding indicates that trust and information sharing are forerunners of SCI (Prajogo \& Olhager 2012:515).

Competitive pricing was identified as the core reason for organisations choosing to integrate with their respective suppliers, often due to market pressures from their customers. Due to the changing business environment, aligning functional business processes allows for a higher level of responsiveness and accuracy in SC decisions in addition to lower risk (Zhao et al. 2011:17-32). It was highlighted that organisations need to make better decisions regarding cash flow and excess inventory. Visibility of inventory and available capacity at the suppliers assisted organisations immensely. The implication of this finding is that organisations are pressured by the business environment to integrate with suppliers in order to realise inventory reductions and create shorter lead times (Jie et al. 2013:1004).

SCI practices changed from tactical to more strategic partner relationships. Participants indicated that they were not aware of integration efforts in their industry or what their competitors were doing. Participants did mention, however, that integration is in the infancy phase and they could still improve their supplier integration initiatives. This finding implies that SCI maturity can be researched in order for organisations to understand their progress towards integration.

Information was shared through both email and personal interactions. The information shared was largely transactional information. Only two participants mentioned that they share business strategies with suppliers. Literature indicates that SC partner strategies need to be included when integration is studied (Huo et al. 2014:370).

Internal information sharing with suppliers was found to be very transactional, and suppliers were more involved when new projects or customer requirements surfaced. Only one participant indicated the existence of computer-to-computer links with suppliers. One participant indicated that his or her organisation did not see the immediate benefit of information technology integration. This is surprising as virtually all the other participants mentioned demand visibility problems as well as overstocked situations as key concerns. This finding indicates that few SC partners invest and implement information systems to align the activities of SC partners with the demands of customers (Behesti et al. 2014:20).

An organisation's strategies and top management support were highlighted as the main elements where integration efforts are concerned. Participants were divided about support from top management but did indicate that they thought SCI forms part of their strategy due to more strategic relationships with suppliers. This finding indicates that the critical issue in literature regarding the correlation between
SCI and organisational performance applies to all industries and environments (Huo et al. 2014:369). One participant indicated that their strategy changed when they decided to enter the retail market.

\section{Practical implications}

The study's findings highlight the relationship between accurate information between supplier and focal firm, and aligning customer demands in the market. Organisations struggling with customer demand visibility and excess inventory, in particular, need to take note of computer-tocomputer links with their suppliers. More information visibility was identified as assisting with demand and inventory problems, as well as facilitating supply lead time reductions through more applicable, visible information. The aforementioned problems emphasise the need for closer partnerships, commitment, and collaboration with suppliers in order to alleviate pressure through competitive pricing and efficient management of available resources.

Management needs to take note when new markets are penetrated to ensure market growth and diversification. The literature indicates that it is not clear whether the positive relationship between SCI and organisational performance applies to all industries. When penetrating a new market, SCI strategies need to be investigated and changed to ensure organisations are equipped to operate in the new market.

Top management support was present in most of the participating organisations, but a few participants indicated a lack of adequate support from top management. Participants felt that 'the customer is king' and processes were changed to accommodate any customer request. This led to pressure on the SC and specifically their suppliers. Literature indicates top management are fully aware that their decisions influence the organisation's strategy, and managerial views need to be changed to ensure effective SCI (Jin et al. 2013:206). Management efforts require a strategic framework as well as management's commitment to link internal and external efforts with SC partners (Behesti et al. 2014:28).

\section{Recommendations}

To explore SC integration efforts, this study specifically focused on commitment, information sharing, top management support and SCI strategy. Future research can explore other dimensions of SCI such as coordination and relationships.

The study was conducted in the plastic manufacturing industry in Gauteng, and participants were chosen for their accessibility as the researcher works in this industry. To validate the findings, the research can be replicated in another industry or with other plastic manufacturers in Gauteng. The research can also be replicated in other settings to determine transferability. The aim of the research was not to generalise the findings and this can be seen as a limitation. A larger study can be done to evaluate the generalisability of the findings. 
While mentioned in the literature review, the relationship between SCI and organisational performance was not investigated in this study. Future research can explore this relationship in the plastic manufacturing industry.

Participants could have claimed top management support for SCI because of a lack of knowledge or because of their loyalty to senior management. This may have biased the findings because top managers' views were not investigated directly. Future research should, therefore, directly explore top management's views on SCI.

\section{Conclusion}

SCI can assist as a tool for organisations to compete in an increasingly competitive environment. According to literature reviewed, there is little evidence of SCI initiatives being implemented. The purpose of this study was to investigate the perceptions of, commitment to and SCI efforts of organisations in the plastic manufacturing industry. A qualitative research design was used to explore the various perspectives from participants as well as to identify the underlying themes from the semi-structured interviews conducted. Findings indicate that the organisations are aware of SCI. Collaboration, trust and commitment were identified as important antecedents of effective SCI. Competitive pricing was identified as a core reason for these organisations to increase integration efforts with their suppliers. This is due to market pressures from their customers. Information sharing and information technology crucial for effective SCI were found to be very transactional, and only one participant mentioned investing in information technology to improve SCI efforts. Participants disagreed on top management support. It is clear from the findings that top management support was more visible when the organisation was actively diversifying into other markets.

\section{Acknowledgements Competing interests}

The authors declare that they have no financial or personal relationships which may have inappropriately influenced them in writing this article.

\section{Authors' contributions}

This article is based on the MPhil dissertation of Y.V., who was therefore the main researcher. W.N. assisted as supervisor with the conceptualisation, literature review and research instrument. T.K. provided methodological and technical guidance.

\section{References}

Alfalla-Luque, R., Marin-Garcia, J.A. \& Medina-Lopez, C., 2012, 'An analysis of the direct and mediated effects of employee commitment and supply chain integration on organisational performance', International Journal of Production Economics 162, 242-257. http://dx.doi.org/10.1016/j.ijpe.2014.07.004

Bagchi, P.K. \& Ha, B.C., 2005, 'Supply chain integration: A European survey', The International Journal of Logistics Management 16(2), 275-294. http://dx.doi.
org/10.1108/09574090510634557
Basnet, C., 2013, 'The measurement of internal supply chain integration', Management Research Review 36(2), 153-172. http://dx.doi.org/10.1108/01409171311292252

Beheshti, H.M., Mostaghel, R., Oghazi, P. \& Hultman, M., 2014, 'Supply chain integration and firm performance: An empirical study of Swedish manufacturing firms', Competitive Review 24(1), 20-31. http://dx.doi.org/10.1108/CR-06-2013-0060

Beth, S., Burt, D.N., Gopacino, W., Gopal, C., Lee, H.L., Lynch, R.P. \& Morris, S., 2003, 'Supply chain challenges: Building relationships', Harvard Business Review 1(7), $4-73$.

Braun, V. \& Clarke, V., 2012, 'Thematic analysis', in H. Cooper, P.M. Camic, D.L. Long A.T. Panter, D. Rindskopf \& K.J. Sher (eds.), APA handbook of research methods in psychology: Research designs: Quantitative, qualitative, neuropsychological, and biological, vol. 2, pp. 57-71, The American Psychological Association, Washington, DC

Chelariu, C., Asare, A.K. \& Brashear-Alejandro, T., 2014, 'A ROSE by another name: Relationship typology and performance measurement in supply chains', Journal of Business \& Industrial Marketing 29(4), 332-343. http://dx.doi.org/10.1108/JBIM08-2013-0178

Cooper, D.R. \& Schindler, P.S., 2014, Business research methods, 12th edn., McGrawHill Education, New York, FL.

Creswell, J.W., 2012, Education research: planning, conducting and evaluating quantitative and qualitative research, Pearson, Boston, MA.

Danese, P. \& Romano, P., 2010, 'Supply chain integration and efficiency performance: A study on the interactions between customer and supplier integration', Supply Chain Management: An International Journal 16(4), 220-230. http://dx.doi. org/10.1108/13598541111139044

Fawcett, S.E. \& Magnan, G.M., 2002, 'The rhetoric and reality of supply chain integration', International Journal of Physical Distribution \& Logistics Management 32(5), 339-361. http://dx.doi.org/10.1108/09600030210436222

Flynn, B.B., Huo, B. \& Zhao, X., 2010, 'The impact of supply chain integration on performance: A contingency and configuration approach', Journal of Operations Management 28(1), 58-71. http://dx.doi.org/10.1016/j.jom.2009.06.001

Geménez, C., van der Vaart, T. \& van Donk, D.P., 2010, 'Supply chain integration and performance: The moderating effect of supply complexity', International Journal of Operations \& Production Management 32(5), 583-610. http://dx.doi.org/ 10.1108/01443571211226506

Guan, W. \& Rehme, J., 2012, 'Vertical integration in supply chains: Driving forces and consequences for a manufacturer's downstream integration', Supply Chain Management: An International Journal 17(2), 187-201. http://dx.doi.org/ 10.1108/13598541211212915

Han, J., Lu, H., Trienekans, J.H. \& Omta, S.W.F., 2013, 'The impact of supply chain integration on firm performance in the pork processing industry in China', Chinese Management Sciences 7(2), 230-252.

Huo, B., 2012, 'The impact of supply chain integration on company performance: An organisational capability perspective', Supply Chain Management: An International Journal 17(6), 596-610. http://dx.doi.org/10.1108/13598541211269210

Huo, B., Qi, Y., Wang, Z. \& Zhao, X., 2014, 'The impact of supply chain integration on firm performance: The moderating role of competitive strategy', Supply Chain
Management: An International Journal 19(4), 369-384. http://dx.doi.org/10.1108/ Management: An Intern
SCM-03-2013-0096

Jie, F., Parton, K.A. \& Cox, R.J., 2013, 'Linking supply chain practices to competitive advantage: An example from Australian agribusiness', British Food Journal 115(7), 1003-1024. http://dx.doi.org/10.1108/BFJ-10-2010-0181

Jin, Y.H.J., Fawcett, A.M. \& Fawcett, S.E., 2013, 'Awareness is not enough: Commitment and performance implications of supply chain integration', International Journal of Physical Distribution \& Logistics Management 43(3), 205-230. http://dx.doi. of Physical Distribution \& Logistics
org/10.1108/IJPDLM-10-2011-0169

Kocoglu, I., Imamoglu, S.Z., Ince, H. \& Keskin, H., 2011, 'The effect of supply chain integration on information sharing: Enhancing the supply chain performance', International Strategic Management Conference 24, 1630-1649.

Klueber, R. \& O'Keefe, R.M., 2013, 'Defining and assessing requisite supply chain visibility in regulated industries', Journal of Enterprise Information Management 26(3), 295-315. http://dx.doi.org/10.1108/17410391311325243

Liu, H., Ke, W., Wei, K.K. \& Hua, Z., 2011, 'Effects of supply chain integration and market orientation on firm performance: Evidence from China', International Journal of Operations \& Production Management 33(3), 322-346. http://dx.doi. org/10.1108/01443571311300809

Mackelprang, A.W., Robinson, J.L., Bernardes, E. \& Webb, G.S., 2014, 'The relationship between strategic supply chain integration and performance: A meta-analytic evaluation and implications for supply chain management research', Journal of Business Logistics 35(1), 71-96. http://dx.doi.org/10.1111/jbl.12023

Moshkdanian, F. \& Molahosseini, A., 2013, 'Impact of supply chain integration on the performance of Bahman Group', Interdisciplinary Journal of Contemporary Research in Business 5(1), 184-192.

Palma-Mendoza, J.A., Neailey, K. \& Roy, R., 2014, 'Business process re-design methodology to support supply chain integration', International Journal of Information Management 34(1), 167-176. http://dx.doi.org/10.1016/j.ijinfomgt.2013.12.008

Papakiriakopoulos, D. \& Pramatari, K., 2010, 'Collaborative performance measurement in supply chain', Industrial Management \& Data Systems 110(9), 1297-1318. http://dx.doi.org/10.1108/02635571011087400

Plano Clark, V.L. \& Creswell, J.W., 2015, Understanding research: A consumer's guide, 2nd ed., Pearson Education, Upper Saddle River, NJ.

Polit, D.F. \& Beck, C.T., 2012, Nursing research: Generating and assessing evidence for nursing practice, 9th edn., Lippincott Williams \& Wilkins, Philadelphia, PA. 
Prajogo, D. \& Olhager, J., 2012, 'Supply chain integration and performance: The effects of long-term relationships, information technology and sharing and logistics integration', International Journal Production Economics 135(1), 514-522. http:// dx.doi.org/10.1016/j.ijpe.2011.09.001

Salam, M.A., 2011, 'Supply chain commitment and business process integration: The implications of Confucian dynamism', European Journal of Marketing 45(3), 358-382. http://dx.doi.org/10.1108/03090561111107230

Simon, A.T., Satolo, E.G. \& Di Serio, L.C., 2014, 'Business process in supply chain integration in sugar and ethanol industry', Business Process Management Journal 20(2), 272-289. http://dx.doi.org/10.1108/BPMJ-04-2013-0043

Tseng, P. \& Liao, C., 2015, 'Supply chain integration, information technology, market orientation and firm performance in container shipping firms', The Internationa Journal of Logistics Management 26(1), 82-106. http://dx.doi.org/10.1108/IJLM09-2012-0088
Vaidya, O. \& Hudnurkar, M., 2013, 'Multi-criteria supply chain performance evaluation: An Indian chemical industry case study', International Journal of productivity
and Performance Management 62(3), 293-316. http://dx.doi.org/10.1108/ and Performance 17410401311309195

Wiengarten, F., Pagell, M., Muhammed, U.A. \& Gimenez, C., 2014, 'Do a country's logistical capabilities moderate the external integration performance relationship?' Journal of Operations Management 32(1), 51-63. http://dx.doi.org/10.1016/ j.jom.2013.07.001

Xu, D., Huo, B. \& Sun, L., 2014, 'Relationships between intra-organisational resources, supply chain integration and business performance: An extended resource-based view', Industrial Management \& Data Systems 114(8), 1186-1206. http://dx.doi. org/10.1108/IMDS-05-2014-0156

Zhao, X., Huo, B., Selen, W. \& Yeung, J.H.Y., 2011, 'The impact of internal integration and relationships commitment on external integration', Journal of Operation Management 29(1), 17-32. http://dx.doi.org/10.1016/j.jom.2010.04.004 


\section{Appendix 1: Discussion guide Introduction}

Interview date:

The purpose of this study is to investigate supply chain integration between plastic manufacturing firms and their suppliers in Gauteng. The focus will specifically be the manufacturers' commitment to and perceptions of supply chain integration as well as of their integration efforts.

Please remember that there is no right and wrong answers, and the interview is to understand your experiences and opinions.

How much time do you have available for this interview?

My estimation is that the interview will take approximately 40-60 min, but the pace of the interview will be adjusted to your time availability and specification.

I need to record the interview to be able to transcribe your opinions and responses for data analysis purposes. The recording is just for me and it will be safeguarded.

Do you approve that this interview can be recorded?

\section{If the participant do not agree to be recorded}

I understand that you do not feel comfortable with me recording this interview so I will need to take notes. These notes will be used for data analysis and data coding purposes. The notes are just for me and the notes will be safeguarded.

The interview will be confidential and no names will be made public. Names will be changed when the research are transcribed thus total anonymity can be ensured. Please note that the interview is voluntary and you may end the interview at any time. You also have the right to decline to answer any specific questions.

May you please sign the informed consent form so we can continue with the interview.

\section{Introduction questions}

The following questions are very specific and will be used to categorise the participants' analysis process and their organisations during the data:

1. Can you give an estimate of how many suppliers are listed as approved suppliers in your organisation?
2. Can you give an estimate of how many employees work in your organisation?

3. Do you have multiple branches in your organisation?

4. What is your job title?

5. How long have you been working for your organisation?

6. How many years of experience do you have liaising with suppliers?

7. What is your educational background?

\section{Main questions}

8. Integration can be seen as bringing together different components into a single system to act as one component. In your opinion, what do you think supply chain integration is all about?

8.1. Can you tell me more about what you think is your organisation's understanding of supply chain integration?

8.2. That is very interesting, can you please tell me more about how integration practices with your suppliers changed over the past $3-5$ years in your organisation?

9. Can you please explain how commitment in your opinion plays a role in supply chain integration efforts with your suppliers?

9.1. Can you please elaborate if your organisation is satisfied with integration efforts with suppliers?

9.2. That is very interesting, please tell me more about what your organisation is doing better than your competitors to improve integration efforts with suppliers?

10. Can you please explain to me how your organisation exchanges information with suppliers?

10.1. That is very interesting, can you give me examples of what information is exchanged with your suppliers?

11. Do you think trust is or is not an important aspect of interacting and sharing information with suppliers?

11.1. That is very interesting, can you elaborate or give me examples of why you think your organisation's relationships with suppliers are based on trust (or not)?

11.2. Can you please tell me a bit more about how your company work with suppliers to improve quality and assist with product design/development?

12. In your opinion, do you think integration efforts must form part of an organisation's strategy?

12.1. That is very interesting, can you tell me more about how your top management team emphasise the importance of integration efforts with suppliers in your organisation?

This is all the basic questions I wanted to ask you. Would you like to say or ask anything or would you like to add any final thoughts on what we have been discussing?

Thank you very much for your time and for participating in this study. Would you like me to send the results of the study to you? 


\section{Appendix 2}

TABLE 1-A2: The link between the codes (sub-themes) and main themes identified in this study.

\begin{tabular}{ll}
\hline Raw data extracts & Codes (sub-themes) \\
'We want transparency, as I say down the supply chain & Competitive pricing \\
that we can see what Company name are paying for & \\
plastics. I'm saying is it helps me across the board & \\
because I get a full pricelist. So, if I'm buying [pause] & \\
packaging plastics, for example, and the guys come & \\
across to me and say they want to put their prices up by & \\
$5 \%$, you know, it means that I've got that transparency & \\
with Company name and I can actually see what they're & \\
doing,so I can control the prices a lot better like that, & \\
as well'. (P9) &
\end{tabular}

'Absolutely, I think uhm, whether it is an international trend or not, but it is just so much harder to do business, overstocking situations. Everyone is more sensitive about where they spend their money'. (P8)

'Yes, definitely, even in the short space of time that I've been here, I've noticed that, definitely. So, there's definitely a drive for us to give forecast and you know understand the reasoning behind it because it's not always that easy to do - to get accurate forecast, but we try our best to get'. (P6)

'Commitment is a huge factor in terms of uhm, maintaining that supply chain. I mean we've got suppliers here that know more about our operations than what I know about it, and that is the level of commitment that we expect from our service providers and partners'. (P10)

'So, that much-, the supplier's quite involved and probably understands the-, they see the end-product, they see who our customer is; they're working with us on that, so there's quite a high-level of trust involved in that'. (P6)

'We look at, within a specific category, uhm, we'll isolate three suppliers and out of that three suppliers, we'll look at the risk, we'll look at threats, we'll look at opportunities and our, strengths. The strengths being from both sides. So it's basically a SWOT analysis that we'll do, and then we'll base the three suppliers on a rating, whoever's rated higher from there, we'll go forward on that'. (P10)

'Ja. I mean, look, as long as it is going to be beneficial for our business, [pause] you know, long term, then [pause] we will go ahead and do it. [Cross talk] you know. And we will al go ahs hapy and comfors will alwaysbe happy and comfortable, whatever is best right intention it is best for the business, you need to it. There is no, there is nor the business, you need to d it. There is no, there is no rocket science theory, you know, [cross talk] it is something that is very, very simple'. (P7)

'Most of these systems rely on the quality of the reporting, the database itself is generally very solid. have used SAP before, uhm, now Syspro, I cannot remember what else but [pause] generally that, that core is very solid, otherwise you do not have any success. But it is the way in which it reports that information that is, that is true. So, he did not understand any of those. He decided he is going to start from scratch, build this Kula system, uhm, focussed primarily on the, on the sales side of things first [cross talk] and getting now the customer involved'. (P8)

'So, there's got to be opportunities for systems to be able to talk to each other where it's needed. I don't think you'll ever take the human element out completely, but certainly, there's lots more integration opportunitie and it's becoming more and more as technology advances'. (P6)

'You see I don't S4 works that way

Not that it is a bad idea, it is probably a very good idea but I don't see S4 doing that. I don't see S4 integrating. I am never involved with any of that.

No, as long as the price is right they are happy'. (P4)
Top management support
Definition Main themes

To set a price for a product or service in line Supply chain partnership what the competition or market is

Shared and available resources Suppliers and customers share each other's in the supply chain resource and/or assist by making resources available between supplier and customer for the benefit of the supply chain.

Sharing of information - first The sharing of supply chain information and second tier between suppliers and customers. This include sorecasts, production plans and business the suppliers', supplier and is a mutual process of sharing.

Supplier and customer The supplier and customer pledge or promise that they will be dedicated to the relationship and the supply chain cause.

Supply chain partnership

Supplier and customer trust

Believing that supplier and customer are reliable, truthful and assured of the other party.

Supply chain information

management

Supply chain partnership

party.

Supplier Collaboration

Working with suppliers to determine improvements beneficial for both customer and supplier.

Supply chain partnership

pply chain partnership

upply chain integration strategy The perceived meaning of supply chain articipants

integration their organisations' strategy.
Technological requirements and Integrating systems and opportunities of advancements for integration integration through technology. Process to bring together different subsystems into one system to function as one system.

\section{System Integration}

Supply chain information management
The perceived support from top management with integration internally and externally.
Supply chain information management

Internal organisationa integration 